\title{
Is there: surgery goes inter- and multidisciplinary
}

\author{
F. M. Riegler
}

Published online: 7 August 2015

(C) Springer-Verlag Wien 2015

The half-time summer stage blues of the year 2015 loves to turn into reggae, as this is the backup of the western colonial civilization, which does not only mirror the European rhythm style phantasy of freedom, it is the freedom to shout it out loud in a very positive groove and vibration, what turns up the soul and the body to get excited about what all these power games managed to master the slaves of the once upon a time victory of the Africans, and then they decided to leave their continent and made their fortune to spread out all over the globe. Going in line with this event, the globe traveled around the sun for more than many million times and shared their space with the moon, the other stars, and the milky way, and it all moved through the never-ending waves of the perception. Religion came to answer the myths of the essence and lately, through the development of the ancient great civilizations, science took off the mask of religion and gave another run of hope, understanding, and knowledge. What remains drops off the gods and the tune of mood and is what you are, at any given instant. Go out there and ask space; go out there and ask time. What else do they serve, as giving you the frame to order your perceptions within the stream of mood. And since we are not allowed to understand being itself, being, the essence of it all, turns out the almost always hidden, except for the moments of interpretation, where the inability to reason being is taken as the limos (i.e., lack, deficit) of our existence. And here we turn to review the past first half of the year. Ister runs past and all over to Linz, before he gets slower and teaches us in the words of Friedrich Hölderlin (1770-1843): unknown and hidden remains, what Ister thinks [1]. Light expresses underworlds.

\author{
F. M. Riegler $(\bowtie)$ \\ Reflux Medical, \\ Mariannengasse 10/9, \\ 1090 Vienna, Austria \\ e-mail: martin.riegler@refluxmedical.com
}

The president and the general secretary of the Austrian Surgical Society are to be congratulated for having put together this year's annual scientific meeting in Linz upon Ister, Upper Austria. Upon the multi-semiotic symbolism of the Ister, a Prague directed sunrise by W. A. Mozart, Anton Bruckner's continuous multi stream network of emotion of his sounding cathedrals ranging from violin to trumpet and Vienna to Bayreuth and the modern present time coverage of cultural expression within the multidimensional Lentos, it happened to become wonderful and outstanding. Prof. Reinhold Függer, Prof. Albert Tuchmann (Fig. 1), and their outstanding team of organizers composed a rainbow spectrum of brilliant presentations, fascinating novelties, and a highly positive outlook for the future of surgical science in Austria and central Europe. The stage took the themes and the actors knew their job and the audience became the orchestra. In addition, the industry is to be acknowledged for their support combining economics and presentation of new technologies and methods, which are going to make the job of the surgeon more effective and easier at hand. The meeting taught the listener and watchers on the great spectrum of life style and eating misbehavior induced disorders of the Central European Civilization. In addition, the congress met the requirements of the present time, since it outlined the novel methods to treat the manifestations of these diseases. Minimally invasive procedures became the routine approach for many oncologic, cardiopulmonary, transplant, vascular, plastic, endoscopic surgical treatments. In addition, the meeting harmonically outbalanced what is makeable versus when to do it. Thus, modern surgery required the wellmanaged interdisciplinary approach.

Going in line with this notion, a well-structured scientific meeting was held at the Medical University Vienna. The group around the skilled and open-minded upper GI surgeon Prof. Dr. Sebastian F. Schoppmann (Fig. 2), staged a novel approach toward gastroesophageal reflux 


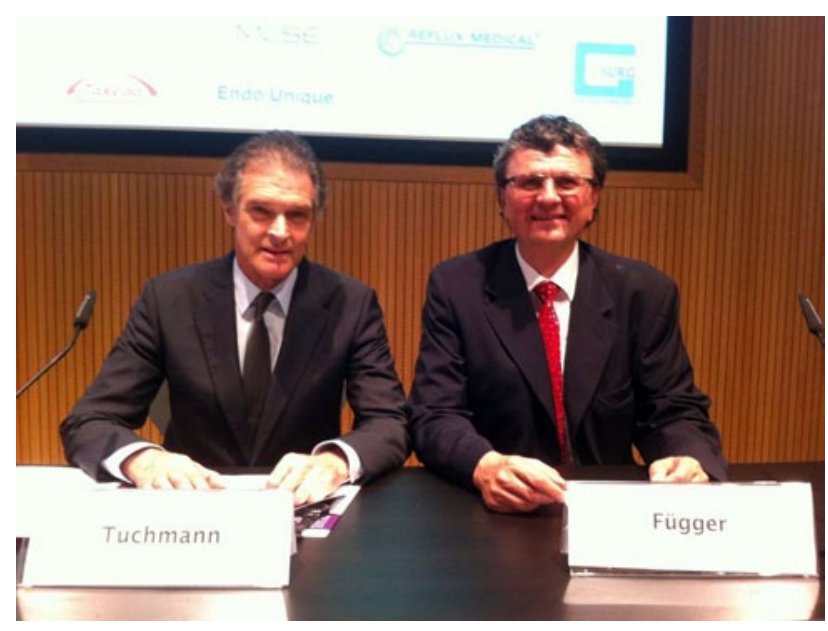

Fig. 1 Prof. Dr. Albert Tuchmann (left), general secretary, and Prof. Dr. Reinhold Függer (right), president of the Austrian Surgical Society. Both academic surgeons are largely involved in the mediation of modern interdisciplinary disease management. Image obtained during a scientific meeting held at the Medical University Vienna, June 2015

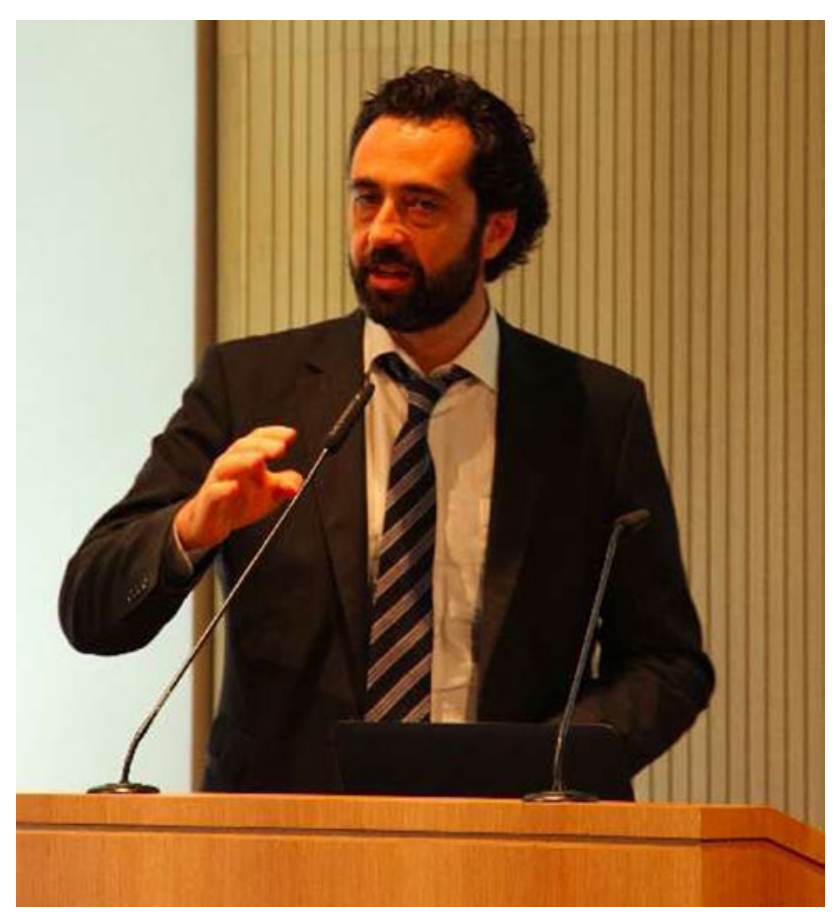

Fig. 2 Prof. Dr. Sebastian F. Schoppmann contributes to the mediation of modern multi-disciplinary approach of disease management, as outlined in the text. Image obtained during a scientific meeting held at the Medical University Vienna, June 2015

disease (GERD), Barrett's esophagus, and esophageal carcinoma. "Reflux multidisciplinary" included different specialities, techniques, and technologies for modern diagnosis, treatment, surveillance, and follow-up of GERD and its manifestations. In addition, the meeting presented novel diagnostic and therapeutic tools. The

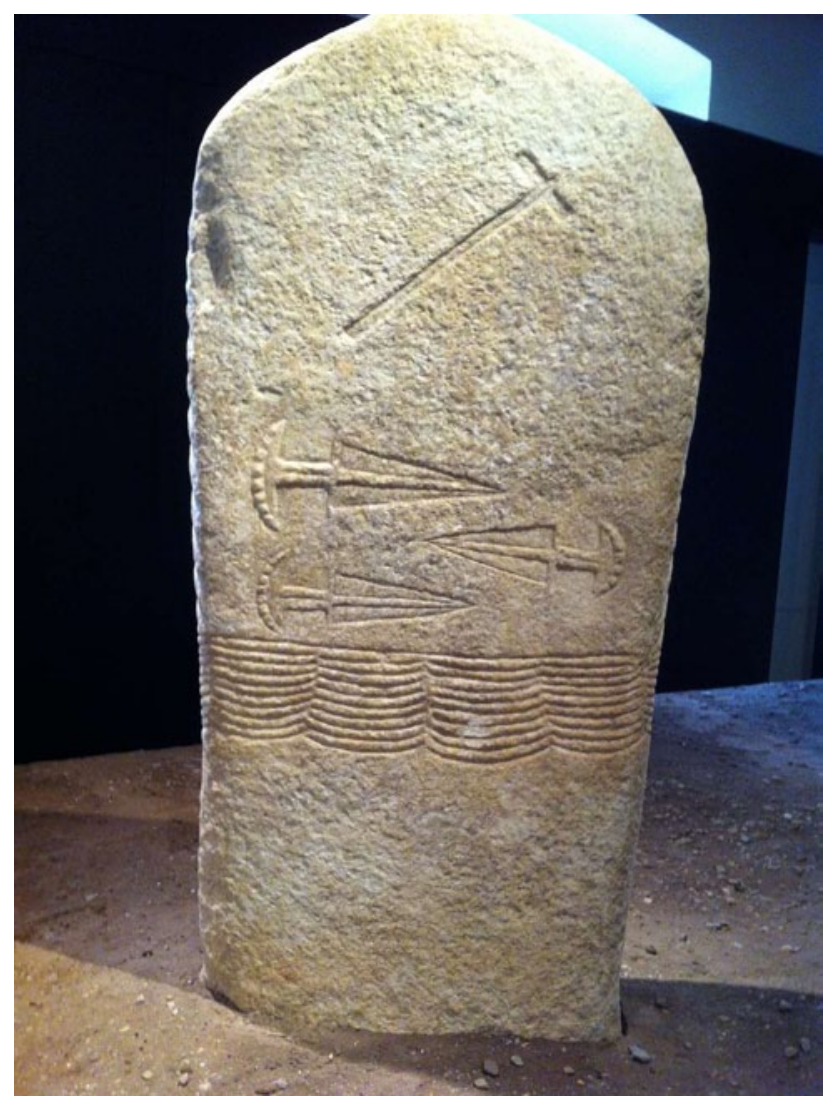

Fig. 3 Ancient stone age carvings (3000-4000 B.C) found next to the city of Riva, Lake Garda. Our ancestors orchestrated the symbolism of rites and the elements of their environment to cartoon the interpretation of their perceptions, as outlined in the text. Image obtained at the museum of history and art in Riva/Lake Garda, northern Italy, EU

importance, actuality, and relevance of the meeting were highlighted by the contribution of the representatives of the Austrian Surgical Society, that is, Prof. Függer and Prof. Tuchmann (Fig. 1). Taken together, the fascinating developments in surgical science should be highly motivating for the young generation. Now politics are at turn to offer the adequate economic and working place logistics and prerequisites. Otherwise, well-trained surgeons will leave the country, and provide their skills elsewhere.

Keeping with the notions of the Linz congress and the Vienna meeting described earlier, the current issue of European Surgery harbors a full spectrum of reports on multidisciplinary themes and topics and thus goes in line with what we need: the open-minded approach toward life, surgery and nature (Fig. 3). Remains to be questioned the essence of it all. All is permanent and manifests as a continuous change along time and space. Beyond our perception streams the mood of emotion. Well-done without concentrated sugar is best, even during summer time! Enjoy your shadows and pick up your tune.

Martin Riegler 


\section{Acknowledgement}

The author thanks his father to motivate the search for the essence, as it outstandingly expresses within the deep multi-semiotic "river poetry" of Friedrich Hölderlin. As thus an individual (patient, friend, child) translates into a continuous river of emotions, wishes, hopes, and desires directed through a pulsatile reality. Lack of adequate attention, acceptance, and understanding fosters the development of a disease and thus should be encountered into diagnosis and therapy in surgery, internal medicine, etc., as considered in the above contribution.

\section{Conflict of interest}

The author declares that there exists no conflict of interest.

\section{Reference}

1. Hölderlin F. Der Ister. Gedichte 1799-1806. In: Balmes HJ, editor Friedrich Hölderlin. Gesammelte Werke. Fischer Taschenbuchverlag. 2008;pp. 209-210. ISBN: 978-3-596-90054-1 